\title{
Application of mineral fertilizers to increasing soil moisture and growth of forest seedlings for creation forest crops in Western Tien-Shan
}

\author{
Bakhram Mamutov ${ }^{1 *}$,Evgeniy Butkov ${ }^{1}$, Abdushukur Hamzayev ${ }^{1}$, Doniyor Sherkuziev ${ }^{2}$, \\ Khayrullakhan Aripov $^{2}$, Farogat Ergasheva ${ }^{3}$, and Karomatkhon Ismoilova ${ }^{3}$ \\ ${ }^{1}$ Research Institute of Forestry, 111104 Tashkent, Uzbekistan \\ ${ }^{2}$ Department of Chemical Technology, Faculty of Chemistry Technology, Namangan Institute of \\ Engineering and Technology, 160115 Namangan, Uzbekistan \\ ${ }^{3}$ Department of Biology, Gulistan State University, 120100 Gulistan, Uzbekistan
}

\begin{abstract}
This article presents the results of research of studying the effect of mineral fertilizers on soil moisture and the growth and development of forest seedlings when creating forest crops on the western slope of the Western TienShan. It was established by experience that forest seedlings react differently to the action of mineral fertilizers. In pine, an increase in the fertilizer dose contributes to an increase in the growth of seedlings in height by 1.2 times. English oak, on the contrary, reacts weakly to the effects of fertilizers. Korolkov's hawthorn reacts intensively to the effects of fertilizers. At the same time, an increased dose of fertilizers contributes to an increase in the annual growth of plants by 3.2 times. The Sievers apple tree differed from other species with intensive growth in all variants of the experiment on the western slopes during the growing season. But in this breed, an increase in the dose of fertilizers caused an increase in annual growth up to 1.5 times compared with the control variant. Mineral fertilizers do not contribute to significant moisture retention in the upper soil layer during the summer vegetation season, but in the lower root-inhabited layers of fertilizer, it has a positive effect in increasing soil moisture above the wilting moisture, which is $8 \%$, and is often observed in the upper horizons.
\end{abstract}

\section{Introduction}

The importance of forests in the foothill and mountainous areas of the republic is enormous. Forests play a critical role in combating desertification and preventing water erosion and mudflows $[1,2,3]$. However, since the direct and indirect human influence is gradually transforming the nature of the mountains and leads to negative consequences [4], it must be emphasized that the current state of the mountain forests of Uzbekistan is alarming. Due to the negative impact of man on the forest, the ecological state of the territories has changed dramatically. At present, unsystematic and overgrazing of livestock exposes and compacts the soil, that is, accelerates the process of degradation $[5,6,7]$. This leads everywhere to a decrease in soil filtration (1.8-3.4 times) to a depth of $30 \mathrm{~cm}$ [8]. In the mountains, there is a

\footnotetext{
*Corresponding author: mamutovb@mail.ru
} 
deterioration in forest growth conditions, which negatively affects the natural regeneration of forests $[9,10,11,12]$. In the lower belt of the mountains, where negative anthropogenic impact is most often observed, natural reforestation does not occur at all. The specific climatic conditions of the territory - high air temperature and low precipitation in the hot summer period further complicate the process and reduce the efficiency for creating protective forests. The survival rate of planted forest saplings to forestry in the mountains using outdated traditional methods is about $35-40 \%$, and sometimes in some years there is a complete death of plants due to lack of precipitation and low soil moisture during the growing season of plants [13]. Therefore, at present, the forest cover of the mountains of Uzbekistan is only 3\% of the total area. Low forest and overgrazing of livestock have recently intensified the process of aridization and soil washout, which is expressed in the desertification of the territory [8].

For sustainable improvement of ecosystems of mountains and foothills, the most effective are forest reclamation works, which are carried out artificially in the basins of small rivers using modern technologies for creating forest plantations with planting material with a closed root system.

Currently, the creation of forest crops with planting material with a closed root system is recognized in many foreign countries, such as Germany, Australia, Switzerland, Finland, France and in recent years Kazakhstan and Kyrgyzstan.

More than 100 different types of containers for growing forest seedlings have been developed in these countries. In addition, in Finland, the proportion of planting seedlings in containers reaches $86 \%$ from the area of creation of new forests, Sweden - 67\%, Canada more than 50\%, Norway - 48\%, Poland - more than 20\%, Russia - about 5\%, Lithuania $3 \%$ [13].

This technology is distinguished by many advantages during the entire frost-free period and a good transfer of post-sedimentary depression [14].

The experience of creating forest plantations with planting material with a closed root system in the mountains of Uzbekistan has not been studied enough. The first studies in this area were carried out in the 1990s, mainly during the restoration of the juniper (Juniperus Chinensis) forests of the republic. On other coniferous and deciduous species, this technology has not been developed at all and many questions remain unresolved. Thus, we initially set ourselves the goal of developing a technology for growing seedlings of coniferous and deciduous species in containers in greenhouse conditions, with the subsequent creation of forest crops from them on arid mountain slopes.

At the same time, the first part of research on the development of technology for growing forest seedlings with a closed root system was performed in 2012-2015 and high results were obtained. The second part of research on the development of effective methods of planting seedlings with a closed root system on arid mountain slopes using mineral fertilizers was carried out in 2015-2017.

The experiments were laid on the western slope of the southern end of the Chatkal ridge, at an altitude of 1400-2000 meters above sea level.

Slope soils belong to brown typical as loam, moderately fertile. In the year of the creation of the experimental forest cultures, more than $840 \mathrm{~mm}$ of precipitation fell, but in the summer, the most intense period, only $29 \mathrm{~mm}$ fell, which did not play any positive role, since they had damped only the soil surface and immediately evaporated. During this period, the moisture content of the upper soil horizons dropped below the wilting moisture.

\section{Materials and Methods}

A Smart Planting seedling of forest crops with closed roots was carried out in 3 different ways in pits measuring $30 \times 30 \times 40 \mathrm{~cm}$ :

Option 1: - the planting was made in such a way that the root collar is on the soil surface; 
Option 2: -planting, as in the first option, but an artificial soil structure former was added to the soil, which the plant was sealed with during planting - a linear colloid powder carboxymethyl cellulose (CMC), which is capable of absorbing moisture in large quantities and keeping it from physical evaporation, saving for the nutrition of seedlings, in the amount of $0.02 \%$ of the mass of the soil, with which the planting hole is filled;

Option 3: - planting was executed in such a way that the whole plant is in a hole, where the root collar is $20 \mathrm{~cm}$ below the soil surface and thus the root system falls into deeper and, accordingly, more humid soil horizons.

As a control, a conventional planting method was tested from a 2-year old open-rooted forest plant nursery used in production.

Planting methods had been tested on 4 forest-forming species:

1. Crimean pine (Pinus Pallasiana);

2. Pedunculate oak (Quercus robur);

3. Korolkov's hawthorn (Crataégus Korolkowii);

4. Apple Sivers (Malus Sieversii).

Planting was carried out on terraces $1 \mathrm{~m}$ wide, created by hand. The distance between the terraces along the slope was $3-4 \mathrm{~m}$. The grade of the slope was 250 . Planting time for crops is the end of March, as soon as the soil has dried out after melted snow.

To accelerate the growth and development of seedlings in crops, we experienced mineral fertilizers in the form of ammonium nitrate, simple granular superphosphate and potassium chloride, which were introduced in the following versions (in $\mathrm{kg}$ of active ingredient per 1 ha):

1. without using fertilizer;

2. N90 P90 K60.

3. N120 P180 K60.

Along with this, the influence of mineral fertilizers on the increase in soil moisture during the growing season was studied. In forest ecosystems, the separation of nitrogen into tree biomass, leaf litter, and root turnover in orchards is likely to affect soil organic matter and, consequently, the accumulation of carbon and moisture in the soil [5]. Fertilizers were applied randomly over the projection area of the seedlings' crowns at the end of March after the snow melted, with their subsequent incorporation into the soil once a year, during the winter dormancy of trees.

\section{Results and Discussions}

The effect of fertilizers on improving the growth of forest crops in the first year was not fully manifested, since growth buds were laid a year before fertilization on a natural background of growth conditions. In the second year after fertilization, growth occurred in plants with increased nutrition in the previous year, and a positive effect manifested itself. As highlighted in Fig. 1, in pine, intensive growth in height was observed with high doses of mineral fertilizers N120P180K60, where the annual growth of seedlings in percentage terms was $51 \%$. At the same time, the annual growth of seedlings was $29 \%$ higher compared to the control variant. There was no significant difference between the options with the use of mineral fertilizers. The use of mineral fertilizers on the pedunculate oak did not have a significant effect on the growth of seedlings. In all variants of the experiment, the growth of seedlings in height during the growing season was slow. A more significant growth was observed only in the first variant, in which a small dose of fertilizers was applied, where the annual growth was $10.9 \mathrm{~cm}$. In the second version of the experience with the use of a large dose of fertilizers the growth of oak seedlings slowed down by the middle of June. By the end of the vegetation, the annual growth of seedlings was only $6.8 \mathrm{~cm}$, whilst a one-year increase in the control version was $7.3 \mathrm{~cm}$ (Fig. 1). 
Only the hawthorn had showed a positive reaction to fertilizer. The most intensive growth of seedlings in height was observed with a large dose of fertilizers, where the annual increase in seedlings in percentage was more than $51 \%$ than in the first version and $63 \%$ more than in control. On the fertilized versions, the intensive growth continued the entire period of vegetation. Whereas on the control, the growth of plants has slowed down by mid-June, and at the end of the year the growing increase was $4.3 \mathrm{~cm}$.

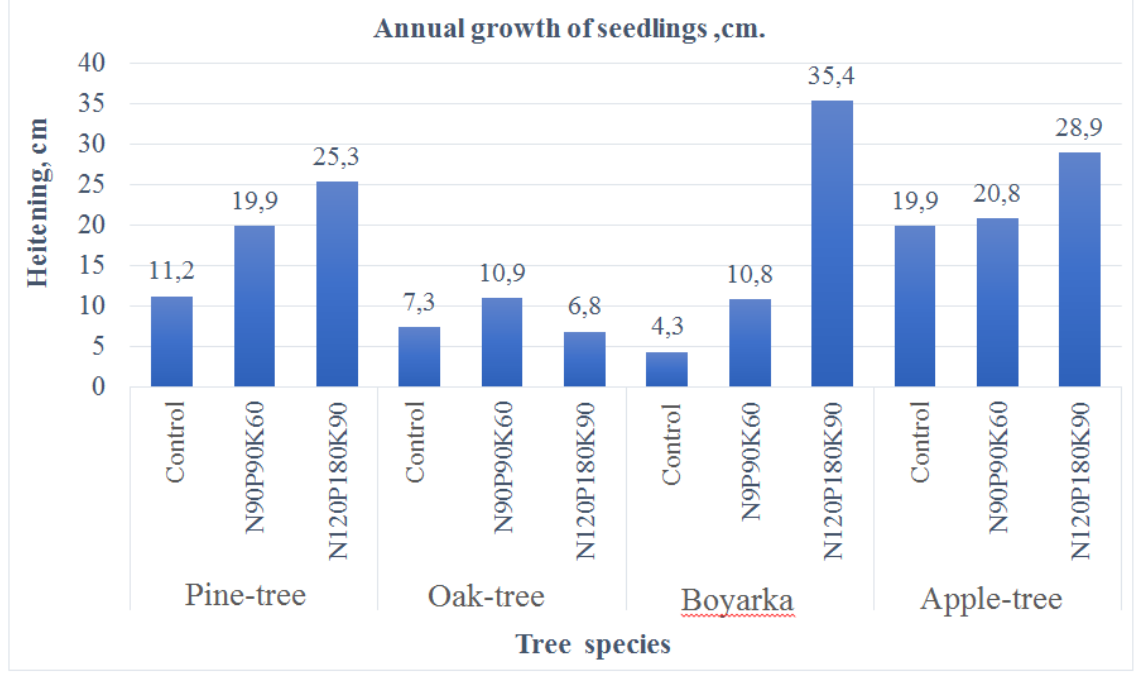

Fig.1. Dynamics of growth of forest tree seedlings when using mineral fertilizers

At the apple-tree, the reaction was better at a large dose of fertilizer. At the same time, fertilizer ensured an increase in the annual growth of seedlings more than $8.1-9 \mathrm{~cm}$ than in other experiments. In this embodiment, sharp growth was observed already at the beginning of the vegetation - in the middle of May and throughout the growing season (Fig. 2).

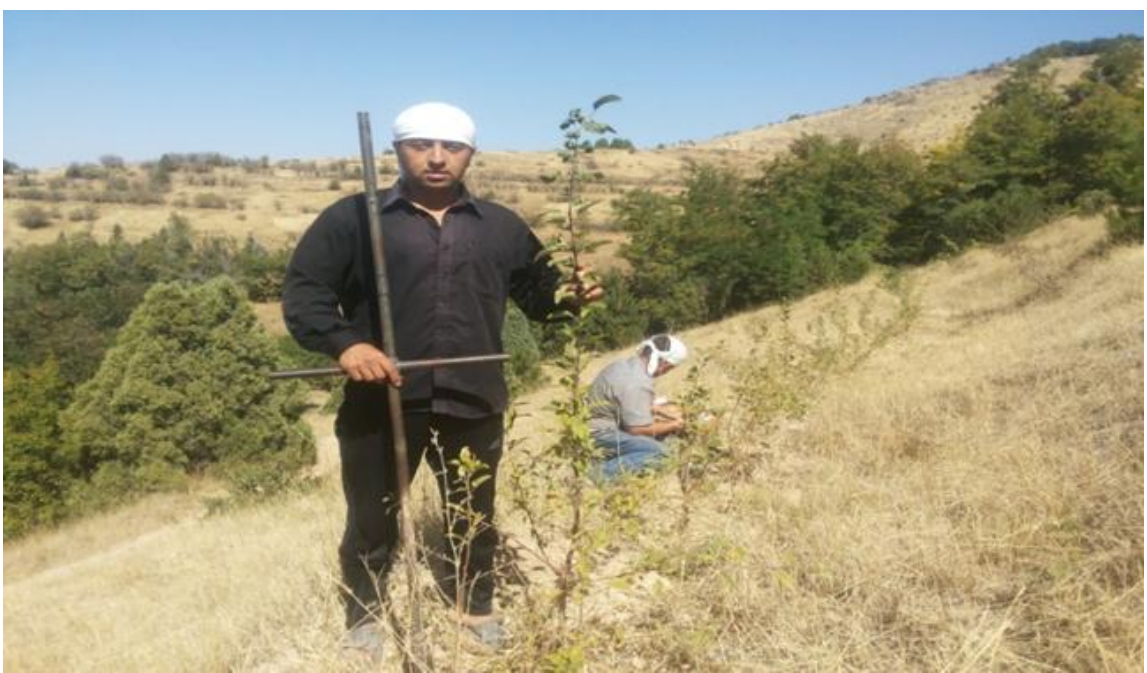

Fig. 2. The growth of Sievers apple tree seedlings in height after application of mineral fertilizers in a dose of $\mathrm{N}_{120} \mathrm{P}_{180} \mathrm{~K}_{90}$ 
Between the first and third options in the increase in the height of substantial differences were not observed. At the same time, the difference in the height of seedlings was $0.9 \mathrm{~cm}$. Due to the fact that mineral fertilizers tend to increase the growth of plants and, accordingly, their root systems, plants consume more moisture both on the construction of an organic matter and on transpiration by an increased amount of sheet apparatus. For this reason, the moisture content of the soil in the growth zone of root systems was studied annually, which is very important in dry zone farming with a lack of moisture in the summer.

The humidity was studied in the middle of one of the surfaces at each version of the experiment on the cultures of the apple tree, as the most dynamically developing type (Fig.3).

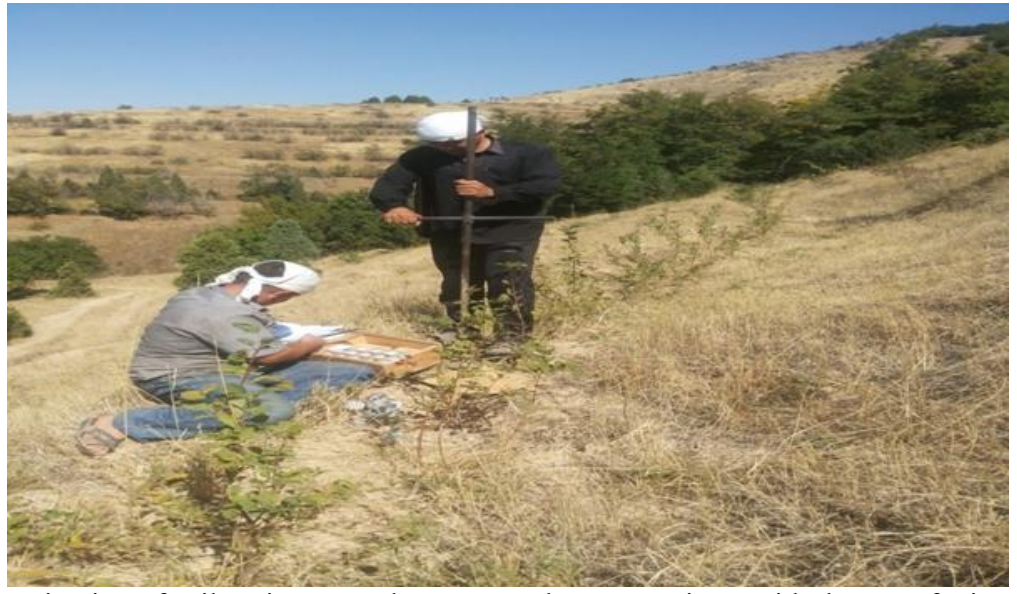

Fig.3. Determination of soil moisture on the western slope on variants with the use of mineral fertilizers

Table1. Indicators of soil moistness in different variation of experience on the western slope

\begin{tabular}{|c|c|c|c|c|c|c|}
\hline \multirow{3}{*}{$\begin{array}{c}\text { Depth of the } \\
\text { soil horizon, } \\
\text { m }\end{array}$} & \multicolumn{6}{|c|}{ Months } \\
\hline & April & May & June & July & August & September \\
\hline & \multicolumn{6}{|c|}{$\mathbf{N}_{90} P_{90} K_{60}$} \\
\hline $0-10$ & 17.60 & 19.25 & 6.38 & 7.03 & 6.45 & 4.72 \\
\hline $10-25$ & 18.37 & 19.29 & 6.70 & 6.89 & 8.76 & 8.09 \\
\hline $25-35$ & 19.82 & 19.90 & 6.72 & 8.38 & 8.39 & 8.38 \\
\hline $35-50$ & 19.93 & 19.64 & 8.15 & 9.88 & 9.83 & 9.61 \\
\hline $50-75$ & 20.12 & 19.99 & 9.24 & 9.54 & 10.38 & 9.66 \\
\hline \multicolumn{7}{|c|}{$\mathbf{N}_{120} \mathbf{P}_{180} K_{90}$} \\
\hline $0-10$ & 18.84 & 18.44 & 6.50 & 6.33 & 6.57 & 5.06 \\
\hline $10-25$ & 18.91 & 18.21 & 7.33 & 6.51 & 9.3 & 8.56 \\
\hline $25-35$ & 19.70 & 18.79 & 8.56 & 8.55 & 10.31 & 9.71 \\
\hline $35-50$ & 19.80 & 18.60 & 8.93 & 9.56 & 9.43 & 10.12 \\
\hline $50-75$ & 20.08 & 19.00 & 9.91 & 10.01 & 10.25 & 10.19 \\
\hline \multicolumn{7}{|c|}{ Control } \\
\hline $0-10$ & 17.30 & 16.29 & 6.30 & 3.89 & 5.04 & 5.05 \\
\hline $10-25$ & 19.78 & 18.79 & 6.27 & 6.64 & 6.46 & 6.37 \\
\hline $25-35$ & 19.80 & 18.70 & 6.92 & 6.47 & 6.50 & 6.53 \\
\hline $35-50$ & 20.42 & 18.72 & 8.20 & 7.46 & 8.31 & 8.22 \\
\hline $50-75$ & 20.56 & 18.76 & 9.34 & 9.20 & 9.14 & 9.32 \\
\hline
\end{tabular}


Soil samples were taken to a depth of $1 \mathrm{~m}$ in the growth zone of root systems, since the plants are still small and their root systems did not spread deeper than $1 \mathrm{~m}$. The humidity was studied in the soil horizons $0-10 ; 10-25 ; 25-50$ and $50-75 \mathrm{~cm}$. The soil moisture on this slope was observed high in April and in May, in the boundaries of the optimal field moisture intensity, due to the large number of precipitation and low vegetation at the beginning of the growing period of transpiration, in all options of the experiment (Table $1)$.

In June and July, when the air temperature increased dramatically and plant transpiration increased, the soil moisture fell significantly. At the options with fertilizer, by using a smaller dose of fertilizers, it was from $6.4 \%$ in the upper horizon to $9.2 \%$ at a depth of 75 $\mathrm{cm}$, getting fall down at the permanent wilting point of soil (in the area of the studies it was $8 \%$ [4] at a depth of $40 \mathrm{~cm}$, and Up to $6.5 \%-9.9 \%$ with a large dose, where the moisture was marked at a depth of $20 \mathrm{~cm}$ ).In the control of the sample, the soil moisture content was observed to the depth of $50 \mathrm{~cm}$ in all horizons. In July, when the transpiration of herbal vegetation decreased, ending with vegetation, on options with fertilizer, the soil moisture in the horizons deeper than $40 \mathrm{~cm}$ increased somewhat, probably due to supplying from the bottom and was higher than the moisture content.

\section{Conclusion and Future Scope}

Thus, from the results of research, it is possible to come to this conclusion, forest seedlings react to the action of mineral fertilizers in different ways. In pine, the increase in the dose of fertilizer contributes to an increase in the growth of seedlings in a height of 1.2 times but Pedunculate oak had conversely showed weak reaction to the actions of fertilizers.

The hawthorn of Korolkova responds intensively to the actions of fertilizers. At the same time, an increased dose of fertilizers contributes to an increase in the annual increase in plants by 3.2 times.

The apple tree of Sivers differs from other breeds with intense growth during the growing season in all versions of experience. In this breed, an increase in the dose of fertilizers led to an increase in one-year increase of 1.5 times more than in the control version. When growing forest crops, the most optimal use of mineral fertilizers in the mountainous conditions of the republic is second-year after planting seedlings.

Making mineral fertilizers on a western slope, where the annual amount of precipitation below $800 \mathrm{~mm}$ is not sufficient to significantly preserve moisture in the upper layer of soil in the summer season of vegetation, in the lower root zone layers, it gives a positive effect in increasing the soil moisture higher than at permanent wilting point of soil.

\section{References}

1 J. W. Dobrowolski, O. Tursunov, O. Pirimov, O. J. Nazarova, Laser Biotechnology for Nutritional Health, Sustainable Environment and Development, IOP Conf. Ser.: Earth Environ. Sci. 614, 012108 (2020)

2 J. W. Dobrowolski, D. Bedla, T. Czech, F. Gambus, K. Gorecka, W. Kiszcak, T. Kuzniar, R. Mazur, A. Nowak, M. Sliwka, O. Tursunov, A. Wagner, J. Wieczorek, M. Swiatek, Integrated Innovative Biotechnology for Optimization of Environmental Bioprocesses and a Green Economy, Optimization and Applicability of Bioprocesses, eds H. Purohit, V. Kalia, A. Vaidya, A. Khardenavis (Singapore: Springer) chapter 3 pp. 27-71 (2017)

3 J. W. Dobrowolski, J. Kobylarczyk, O. Tursunov, S. Q. Toh, Integration of Local EcoInnovation with Global Problems of Protection of the Natural Environment and BioBased Green Economy, In Proceedings : AASRI International Conference on Circuits and Systems (CAS), Atlantis Press 9, 25-28 (2015) 
4 B. Martín-López, I. Leister, P. Lorenzo Cruz, I. Palomo, A. Grêt-Regamey, P. A. Harrison, et al., Nature's contributions to people in mountains: A review, PLoS ONE 14(6), e0217847 (2019)

5 D. Sh. Sherkuziev et al., Research of agrochemical and mechanical properties of soils processed with hydrogel, IOP Conf. Ser.: Earth Environ. Sci. 614, 012121 (2020)

6 Kh. A. Otaboyev, D. Sh. Sherkuziev et al., Obtaining simple superphosphate granulated by two-step processing of phosphorite flour, Scientific Bulletin of NSU 5, 98-103 (2021)

7 D. Sh. Sherkuziev et. al., Preparation of hydrogel polymer by polymerization of hydrolyzed polyacrylonitrile with formalin in the presence of glycerin, German International Journal 9, 7-10 (2021)

8 K. J. Nadelhoffer, B. P. Colman, W. S. Currie, A. Magill, J. D. Aber, Decadal-scale fates of $15 \mathrm{~N}$ tracers added to oak and pine stands under ambient and elevated $\mathrm{N}$ inputs at the Harvard Forest (USA), For. Ecol. Manag. 196, 89-107 (2004)

9 L. A. Adilbekov, S. L. Alibekova, Problems of sustainable development of pastures of the mountains and foreigners of Uzbekistan, J. Economic Problems of Sustainable Development of Mountainous Areas, Agro-industrial Complex 2(4), 15-21 (2010)

10 X. Yang, D. Yan, C. Liu, Natural Regeneration of Trees in Three Types of Afforested Stands in the Taihang Mountains, China, PLoS ONE 9(9), e108744 (2014)

11 M. Löf, P. Madsen, M. Metslaid, et al. Restoring forests: regeneration and ecosystem function for the future, New Forests 50, 139-151 (2019).

12 L. Robin Chazdon et al., Fostering natural forest regeneration on former agricultural land through economic and policy interventions, Environ. Res. Lett. 15, 043002 (2020)

13 B. H. Mamutov, Perspective ways to create forest crops in the mountains of Uzbekistan by planting material with a closed root system, Candidate of Science Dissertation, Tashkent (2019)

14 D. S. Burtsev, T. S. Masaralyev, Overview of the global practice of growing oak seedlings with a closed root system, International Conference on Innovations and Technologies in Forestry, St. Petersburg, pp. 111-122 (2013) 